\title{
Empirical Research on the Impact of Free Cash Flow on Operating Performance of Listed Companies
}

\author{
Qu Yi ${ }^{\mathrm{a}}$, Jia Bingbing ${ }^{\mathrm{b}}$, and Zhang Jianruic \\ Harbin Vocational College of Science and Technology, Harbin, China 150300 \\ aemail: 26444806@qq.com, bemail:Jiabingbing@hrbkjzy.com, cemail:Zhangjiarui@hrbkjzy.com
}

Keywords: Free cash flow; Business performance; Listed companies; Multiple linear regression

\begin{abstract}
Free cash flow can not only assess the past now ability, enterprise can also be built into the evaluation system of the future development of ability, relative profits and cash flow indicators, reflect the business performance of the free cash flow is more comprehensive and effective. Therefore, it is of great significance and value for all stakeholders to study the effect of free cash flow on business performance. In 2794 listed companies in China in 2016 financial data as sample, using multivariate regression method for the empirical analysis, finally draw the conclusion: free cash flow and enterprise management performance has significant positive correlation; The expansion of enterprise scale has a positive effect on business performance, but debt will reduce business performance. The increase of the shareholding ratio of the largest shareholder can improve the corporate performance, while the independent directors cannot effectively play their functions. Therefore, operators should appropriately hold free cash flow, appropriately expand the operation scale, and improve and give play to the independent director system can effectively improve the operation performance of enterprises.
\end{abstract}

\section{Introduction}

The evaluation of business performance comes from the agency behavior caused by the separation of two rights in the modern enterprise system environment and the need of the enterprise owners to improve their capital control. A series of financial scandals, such as "Enron incident", "WorldCom" and "silver Guangxia", which took place in our country early in the United States, have made people realize that the traditional evaluation system with profit as the main index has some limitations in practice. In the 2008 financial crisis, many enterprises were on the verge of bankruptcy or even bankruptcy because of the capital chain problem. Although on the surface, this is the inevitable adverse effect of the financial crisis, the real reason for the collapse of the enterprise is the management of cash flow caused by excessive expansion and investment errors. Therefore, we need to find an evaluation index system that not only can effectively solve the traditional profit indicators, but also can overcome the short-term behavior of business operators and thus to whitewash the financial behavior. From the basic meaning of free cash flow, it refers to the cash flow that can be produced by enterprises other than the necessary asset input such as inventory, plant, machine equipment and long-term equity investment.

\section{Model Construction}

If there are two or more than two independent variables in the regression analysis, the regression is called multivariable linear regression model, and a kind of economic phenomenon is often caused by the joint effect of many factors. Therefore, the analysis of dependent variables by means of multiple independent variables is more effective and practical than using only one independent variable.

The general form of multiple linear regression model is as follows:

$$
Y=\beta_{0}+\beta_{1} x_{1}+\beta_{2} x_{2}+\cdots+\beta_{p} x_{p}+\varepsilon
$$


Among them, $\beta \_0, \beta \_1, \cdots, \beta \_\mathrm{p}$ is a $\mathrm{p}+1$ unknown parameter; $\beta \_0$ is called a regression constant; and $\beta \_1, \cdots, \beta \_$pis called the regression coefficient of the explanatory variable; $\mathrm{Y}$ is an explanatory variable, i.e., the dependent variable, $\mathrm{x} \_1, \mathrm{x} \_2, \cdots, \mathrm{x} \_$pis an explanatory variable that can be accurately measured and controlled, namely the independent variable. The $\varepsilon$ is the error term of the regression equation.

In the analysis of the actual problems, if we can obtain the observation data of the $\mathrm{N}$ group,

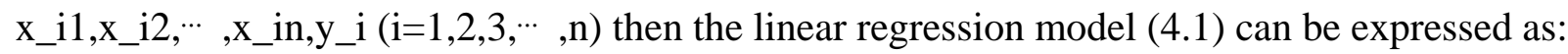

It is assumed that the function of multiple sample regression is as follows:

$$
\left\{\begin{array}{c}
Y_{1}=\beta_{0}+\beta_{1} x_{11}+\beta_{2} x_{12}+\cdots+\beta_{p} x_{1 p} \\
Y_{2}=\beta_{0}+\beta_{1} x_{21}+\beta_{2} x_{22}+\cdots+\beta_{p} x_{2 p} \\
Y_{n}=\beta_{0}+\beta_{1} x_{n 1}+\beta_{2} x_{n 2}+\cdots+\beta_{p} x_{n p}
\end{array}\right.
$$

The form of a matrix is as follows:

$$
Y=X \beta+\varepsilon
$$

Among them:

$$
\mathrm{Y}=\left[\begin{array}{c}
y_{1} \\
y_{2} \\
\vdots \\
y_{n}
\end{array}\right] \quad \beta=\left[\begin{array}{c}
\beta_{1} \\
\beta_{2} \\
\vdots \\
\beta_{n}
\end{array}\right] \quad \varepsilon=\left[\begin{array}{c}
\varepsilon_{1} \\
\varepsilon_{2} \\
\vdots \\
\varepsilon_{n}
\end{array}\right] \quad \mathrm{X}=\left[\begin{array}{ccc}
1 & \cdots & x_{1 p} \\
\vdots & \ddots & \vdots \\
1 & \cdots & x_{n p}
\end{array}\right]
$$

Matrix $X$ is $n \times(p+1)$ matrix, $X$ is called regression design matrix or data matrix. And in the empirical process, the elements of $X$ are preset and controllable, because the subjective factors of people are involved in it, which is also called the design matrix.

Free cash flow is closely related to the performance of the enterprise. In recent years, China's listed companies have also begun to manage free cash flow, so it is necessary to analyze the influence of free cash flow on business performance. The multiple linear regression model is more convenient and concise. It is easy to measure the influence of enterprises' free cash flow, enterprise scale and asset liability ratio on business performance. Therefore, in order to investigate the impact of the current situation of free cash flow on the performance of the listed companies in China, and take into account other control variables, this paper establishes the multiple linear regression model of cross section data as follows:

$$
R O A=\beta_{0}+\beta_{1} F C F+\beta_{2} D E B T+\beta_{3} L n S I Z E+\beta_{4} F S H+\beta_{5} I D R+\varepsilon
$$

Among them, the regression coefficient of the $\beta$ representative parameters, ROA as the explanatory variable, is the total asset return rate, that is, the total assets of the year end of the enterprise. FCF is the main explanatory variable, the relative value of free cash flow, compared with the total assets of the enterprise by free cash flow; DEBT is the asset liability rate of the enterprise; InSIZE represents the enterprise. The scale of the industry is expressed by the logarithm of the total assets of the enterprise at the end of the year; FSH is the first largest shareholder's shareholding ratio; IDR represents the proportion of the independent directors to the number of the board of directors; the epsilon represents a random disturbance.

\section{Empirical analysis}

Each index is selected as table 1.

This paper will add control variables step by step to carry out regression test and analysis of multivariate equation models. Table 2 is an equation model checklist that can be found clearly. The interpretations and control variables selected in this paper are strongly correlated with the explanatory variables and have passed the significance test. In addition to the proportion of independent directors (IDR), this index is significant in the range of $5 \%$, and the test results of other 
indicators are less than 0.01. It shows that the multivariate regression model is better for explaining the dependent variable, and the fitting result has better economic significance.

Table 1 variable definition table

\begin{tabular}{ll}
\hline \multicolumn{1}{c}{ variable } & \multicolumn{1}{c}{ calculation formula } \\
\hline Explained variableROA & ROA $=$ net profit $/$ final total assetsROA \\
Explanatory variablesFCF & FCF $=$ free cash flow absolute value $/$ final total assets \\
Control variable DEBT & DBET $=$ total final Liabilities $/$ final assets \\
Control variable InSIZE & SIZE $=$ In (final total asset) \\
Control variable FSH & FSH $=$ first shareholders account for share percentage \\
Control variable IDR & IDR $=$ number of independent directors $/$ total number of directors \\
\hline
\end{tabular}

Note: when calculating financial indicators, the final amount will be used.

Table 2 Checklist of multivariate equation model test

\begin{tabular}{cccccc}
\hline & model(6) & model(7) & model(8) & model(9) & model(10) \\
\hline \multirow{2}{*}{ FCF } & $0.063^{* * *}$ & $0.076^{* * *}$ & $0.080^{* * *}$ & $0.078^{* * *}$ & $0.078^{* * *}$ \\
& $(1.910)$ & $(10.176)$ & $(10.938)$ & $(10.611)$ & $(10.591)$ \\
DEBT & & $-0.103^{* * *}$ & $-0.137 * * *$ & $-0.136^{* * *}$ & $-0.136^{* * *}$ \\
& & $(-19.731)$ & $(-23.655)$ & $(-23.510)$ & $(-23.572)$ \\
InSIZE & & $0.011^{* * *}$ & $0.011^{* * *}$ & $0.011^{* * *}$ \\
& & $(12.263)$ & $(11.082)$ & $(11.053)$ \\
FSH & & & $0.026^{* * *}$ & $0.027^{* * *}$ \\
& & & $(3.422)$ & $(3.422)$ \\
IDR & & & & $-0.047^{* *}$ \\
& & & & & $(-2.412)$ \\
C & $0.035^{* * *}$ & $0.079 * * *$ & -0.159 & $-0.151^{* * *}$ & $-0.133^{* * *}$ \\
& $(30.038)$ & $(31.920)$ & $(-8.123)$ & $(-7.634)$ & $(6.280)$ \\
R ${ }^{2}$ & 0.022 & 0.142 & 0.186 & 0.189 & 0.191 \\
& & & & & 131.407 \\
F Test & 62.857 & 230.451 & 211.80 & 162.523 & 2793 \\
\hline Obs & 2793 & 2793 & 2793 & 2793 &
\end{tabular}

Note: $* * *, * *, *$ respectively indicate that the $\mathrm{t}$ test results are significant in brackets at $1 \%, 5 \%$ and $10 \%$.Data source: the author calculates through SPSS software

Through the above empirical results, the following equations are finally sorted out.

$$
\mathrm{ROA}=-0.133+0.078 F C F-0.136 \text { DEBT }+0.011 \text { InSIZE }+0.027 F S H-0.047 \text { IDR }+\varepsilon(6)
$$

Through the test and analysis of the single factor model and the multivariate equation model, we can find that the regression coefficient of free cash flow is positive, and there is a significant positive correlation between $\mathrm{p}<0.01$, that is, free cash flow and business performance. The relative value of free cash flow can be raised by $1 \%$, which can produce business performance. The improvement of birth $0.078 \%$. Therefore, the increase of free cash flow holdings is beneficial for enterprises to improve their business performance. The asset liability ratio (DEBT) of the enterprise is the regression coefficient $\beta \_3=-0.136$, which is significant in the $1 \%$ interval, indicating that the enterprise's liabilities have obvious negative effects on the business performance. The scale of the enterprise (InSIZE) is to express the size of the enterprise by selecting the logarithm of the total assets at the end of the enterprise. The more the total assets of the enterprise at the end of the year show the larger the scale of the enterprise, and in the empirical results, the scale of the enterprise has a significant positive correlation with the business performance of the enterprise, and its coefficient of 
beta shows the improvement of the business scale of the enterprise. It has a positive effect on the business performance of an enterprise. The proportion of the first shareholders (FSH), that is, the proportion of the first shareholders in the total shares, represents the rights of the first shareholders of the enterprise.

\section{Conclusion}

Free cash flow has experienced more than 30 years of history. It mainly comes from the cash flow produced by business activities, and it is based on the payment realization system, which is difficult to manipulate, and can accurately reflect the business performance of the enterprise. Based on this, this paper selects the majority of the manufacturing industry as the research sample, and adopts the empirical study to collect the financial data of the Shanghai and Shenzhen listed companies in 2016. Through the SPSS statistics, the total asset reward rate represents the business performance of the enterprise, and the free cash flow is used as the independent variable for multiple linear regression. This will explore the impact of free cash flow on business performance. The following conclusions are drawn. First, the free cash flow has a significant positive correlation with the business performance, so holding a certain amount of free cash flow will help enterprises to improve their investment ability, seize market opportunities, and thus improve the business performance of the enterprises. Second, the business performance will be affected by the scale of the enterprise. On the one hand, the large enterprises have more discourse power in the internal and external financing. The small cost of financing is beneficial to improve the performance. Secondly, the impact of economies of scale is also a part of the reason. Third, debt will lead to a reduction in business performance, which is closely related to the traditional belief that debt is a misconception in the capital market. Fourth, the role of independent director system in improving business performance is not obvious. In Chinese listed enterprises, independent directors can not play their functions effectively.

\section{Acknowledgements}

Heilongjiang Province ordinary undergraduate colleges and universities young innovative talents training plan. Research on the allocation efficiency of financial resources in China from the perspective of contract theory (item number: UNPYSCT-2016058), host Zhong Shen.

Heilongjiang Education Science 12th Five-Year plan topic. Research on "effective training of skilled talents in Higher Vocational Colleges" (item number: ZJC1215003), host Qu Yi

Study on the Countermeasures of Vocational Education Collectivization - Taking Harbin Modern Service Vocational Education Group as an example numbering the planning subject of the Provincial Education Department of the "13th Five-Year" program of education science of Heilongjiang Province. (Item number: ZJC1316055), host Zhu Jinghu.

\section{References}

[1] Jensen M. Agency Costs of Free Cash Flow, Corporate Finance and Takeovers [J]. American Economic Review, 1986.

[2] Steven B., David R. Peterson. Self-tender offers: The effects of free cash flow, cash flow signaling, and the measurement of Tobin's q [J]. Journal of banking and finance, 1995, (19): 1005-1023.

[3] Schwetzler B., Reimund C. Valuation Effects of Corporate Cash Holdings: Evidence from Germany. Working Paper, 2004.

[4] Chung R., Firth M., Kim J. Earnings Management, Surplus Free Cash Flow, and External Monitoring [J]. Journal of Business Research, 2005, (23): 766-776.

[5] Denis D., Sibilkov V.Financial Constraints, Investment and the Value of Cash Holdings [J]. Review of Financial Studies, 2010. 